\title{
Eficiência das Sociedades Cooperativas e de Capital na Indústria de Laticínios
}

\author{
Marco Aurélio Marques Ferreira*, Marcelo José Braga ${ }^{\dagger}$
}

Sumário: 1. Introdução; 2. Eficiência nas sociedades; 3. Resultados e Discussão; 4. Conclusões. Palavras-chave: Cooperativas; Eficiência; Laticínios. Códigos JEL: Q13.

Este trabalho objetivou analisar a eficiência das cooperativas diante das sociedades de capital na indústria de laticínios. O estudo fundamentouse nas bases conceituais de eficiência nos diferentes modelos societários, interpretadas e contextualizadas à luz da teoria da agência e dos direitos de propriedade, contando com a participação de 107 unidades produtivas brasileiras. A mensuração da eficiência deu-se pela Análise Envoltória de Dados. Os resultados confirmaram a hipótese de que as cooperativas são menos eficientes que as sociedades de capital no quesito eficiência produtiva, asseverando, assim, a importância de promover políticas diferenciadas para a melhoria da eficiência na indústria de laticínios.

The objective of this work is to analyze the efficiency of cooperatives and non cooperatives in the Brazilian dairy industry. In the study, the conceptual bases of efficiency in the two different organizational forms are interpreted based on agency and property rights theories. The efficiency was measured by using Data Envelopment Analysis in a sample of 107 fluid milk processors. The results support the hypothesis that the cooperatives are less efficient than the non cooperatives in productive efficiency. The paper argues about the importance of promoting differentiated politics for the improvement of the efficiency in the dairy industry.

\section{INTRODUÇÃO}

Ao longo das últimas décadas, o avanço das sociedades de capital, sobretudo das multinacionais, e a redução da participação das cooperativas na captação e no processamento de leite, em mercados

\footnotetext{
* Administrador, Doutor em Economia Aplicada, Prof. Adjunto do Departamento de Administração da Universidade Federal de Viçosa (UFV). E-mail: marcoaurelio@ufv . br. Endereço: Departamento de Administração - UFV, Campus Universitário 36570000 Viçosa, MG - Brasil.

${ }^{\dagger}$ Doutor em Economia Rural, Prof. Adjunto do Departamento de Economia Rural da Universidade Federal de Viçosa (UFV), E-mail: mjbraga@ufv .br. Endereço: Departamento de Economia Rural - UFV, Campus Universitário 36570-000 Viçosa, MG - Brasil.
} 
localizados, têm exigido dos pesquisadores resposta à seguinte questão: são as cooperativas menos eficientes que as sociedades de capital? Na realidade, não existe consenso suficiente para formular uma resposta categórica e precisa, visto que esse assunto permeia uma série de fatores de natureza complexa.

No Brasil, por exemplo, muito se tem questionado em relação à eficiência das cooperativas e, por conseqüência, do modelo cooperativista no que diz respeito ao processamento e à comercialização de produtos lácteos, em razão de uma série de limitações abordadas à luz da teoria da agência e dos direitos de propriedade. $O$ fato é que a incapacidade de acompanhar o dinamismo do setor, somada à baixa articulação do sistema, tem levado muitas cooperativas a se concentrar na fase de captação de leite em função de dois fatores principais: fragilidade financeira, operacional ou gerencial e posicionamento estratégico defensivo.

Todavia, não se pode afirmar que o modelo cooperativista seja menos eficiente que as sociedades de capital, visto que os resultados dos estudos ainda são muito contraditórios e de natureza limitada. Na realidade, não existe, na literatura econômica, consenso sobre a eficiência ou ineficiência das sociedades cooperativas quando comparadas às sociedades de capital, o que motiva uma investigação nesse sentido. O problema em questão trata não apenas de mensurar a eficiência na indústria de laticínios, mas de identificar os comportamentos associados à eficiência e à ineficiência das sociedades cooperativas diante das sociedades de capital, visando gerar informações que contribuam efetivamente para ganhos de eficiência e competitividade no setor.

\section{EFICIÊNCIA NAS SOCIEDADES}

Existem diversas características que possibilitam a distinção entre sociedades cooperativas e sociedades de capital, sendo as principais delas apresentadas, sinteticamente, na Tabela 1.

Na ótica da sociedade cooperativa, a eficiência é vista como a combinação da racionalidade econômica com os valores de ajuda mútua, solidariedade, liberdade, igualdade e justiça. Por meio do princípio sinérgico, "o todo é maior que a soma das partes", os cooperados se unem voluntariamente para constituir um empreendimento sólido e competitivo, de natureza econômica e social. As sociedades de capital, por sua vez, distribuem seus resultados em função da participação do capital de cada sócio na consecução de seus resultados.

Dessa maneira, dentro da premissa de premiação ao risco ou da prorrogação da liquidez, os resultados líquidos da sociedade de capital são rateados em função da participação do capital na empresa e suas decisões seguem essa mesma orientação. Em uma sociedade por ações, diferentemente das cooperativas, as deliberações se dão em função das ações e não das pessoas, ou seja, cada ação representa um voto e, assim, o capital pode ser encarado como uma fração de poder de decisão.

Acredita-se que algumas dessas características conferem vantagens ao modelo de gestão das sociedades de capital, o que poderia ser associado a ganhos de eficiência na utilização dos seus recursos quando comparadas às sociedades cooperativas, conforme discorrido na teoria da agência e dos direitos de propriedade.

Essas teorias têm como ponto de partida o fundamento de que uma firma pode ser vista como um conjunto de contratos, que envolvem empregados, proprietários, clientes, colaboradores, administradores, comunidade, entre outros (Jensen e Meckling, 1979). De acordo com Condon (1987), a cooperativa é um conjunto de contratos que regem os direitos de propriedade e controle sobre os recursos, envolvendo os aspectos de tomada de decisão, alocação de recursos, divisão de retornos e apropriação de ganhos e riscos.

Conforme apontado por Sykuta e Cook (2001), nem todas as cooperativas são caracterizadas pelos mesmos direitos de propriedade e estrutura organizacional, daí a necessidade de modelar contratos específicos a cada uma dessas organizações, como forma de maximizar a eficiência da sociedade. 
Tabela 1 - Principais características das sociedades cooperativas e das sociedades de capital

\begin{tabular}{|c|c|}
\hline Sociedade cooperativa & Sociedade de capital \\
\hline Regida pela Lei 5.764/71 e pela Lei $10.406 / 2002$. & $\begin{array}{l}\text { Regida pelo Código Comercial Brasileiro e pelas } \\
\text { Leis } 10.303 / 2001 \text { e } 10.406 / 2002 \text {. }\end{array}$ \\
\hline $\begin{array}{l}\text { O elemento central do modelo societário é o ho- } \\
\text { mem. }\end{array}$ & $\begin{array}{l}\text { O elemento central do modelo societário é o ca- } \\
\text { pital. }\end{array}$ \\
\hline Constituída por 20 ou mais pessoas. & Constituída por duas ou mais pessoas. \\
\hline Voto por pessoa. & Voto por cota ou ação. \\
\hline $\begin{array}{l}\text { Controle democrático, com base no elemento hu- } \\
\text { mano. }\end{array}$ & Controle subordinado à participação do capital. \\
\hline $\begin{array}{l}\text { A remuneração do capital integralizado é limi- } \\
\text { tada a } 12 \% \text { a.a. }\end{array}$ & $\begin{array}{l}\text { Não existe limitação à remuneração do capital in- } \\
\text { tegralizado. }\end{array}$ \\
\hline As cotas não podem ser transferidas a terceiros. & $\begin{array}{l}\text { As cotas podem ser transferidas a terceiros, res- } \\
\text { peitando a legislação vigente. }\end{array}$ \\
\hline $\begin{array}{l}\text { Investimentos orientados pelas necessidades dos } \\
\text { cooperados. }\end{array}$ & $\begin{array}{l}\text { Investimentos orientados pelas oportunidades } \\
\text { mercadológicas. }\end{array}$ \\
\hline $\begin{array}{l}\text { Os resultados (sobras) retornam aos sócios pro- } \\
\text { porcionalmente às suas operações. }\end{array}$ & $\begin{array}{l}\text { Os resultados (lucro) retornam aos sócios propor- } \\
\text { cionalmente ao número de ações ou quotas na } \\
\text { sociedade. }\end{array}$ \\
\hline $\begin{array}{l}\text { Visa à remuneração melhor ao produtor, promo- } \\
\text { vendo o bem-estar econômico. }\end{array}$ & $\begin{array}{l}\text { Visa à maximização do lucro em detrimento do } \\
\text { bem-estar econômico. }\end{array}$ \\
\hline $\begin{array}{l}\text { Defende a eqüidade entre objetivos econômicos } \\
\text { e sociais. }\end{array}$ & $\begin{array}{l}\text { Defende o compromisso com o econômico, sub- } \\
\text { metendo a ele os demais objetivos societários. }\end{array}$ \\
\hline
\end{tabular}

${ }^{a}$ Fonte: Elaborado pelo autor.

Todos esses contratos são estabelecidos entre a empresa e seus stakeholders, sendo que os proprietários da sociedade receberão os resultados residuais das operações da firma, e os demais contratantes, algum tipo de remuneração previamente estabelecida.

A teoria da agência se dedica aos fatores relacionados a um contrato específico, qual seja: o contrato entre o agente ("empoderado" para defender os interesses do principal) e o principal (proprietário da firma). Assim, por meio de um contrato, é delegado ao agente a administração do empreendimento do principal. No centro da teoria está o pressuposto da informação assimétrica, ou seja, o agente possui maior conhecimento do negócio do que o principal, estando apto a agir oportunistamente em qualquer momento (Nilsson, 1999).

Dessa forma, o principal tem que construir mecanismos de proteção contra perdas que possam resultar dos desvios de comportamento do agente. Todavia, essas medidas requerem recursos, e o principal se vê obrigado a arcar com uma variedade de custos de agência. De acordo com Fama e Jensen (1983) e Shleifer e Vishny (1996), os custos de agência são encontrados em todas as sociedades, embora o seu dimensionamento varie entre elas. Isso se deve à existência de uma variedade de ações implementadas no sentido de reduzir os riscos de perdas envolvidos na separação entre propriedade e controle, que tem suas peculiaridades de acordo com o modelo societário da organização.

No caso das cooperativas, o custo de agência é agravado pela gestão administrativa não-profissional, em razão de os próprios cooperados assumirem a direção da organização sem que tenham, na maior parte dos casos, formação ou experiência adequada para essa função. Como no Brasil a exigência de publicação dos relatórios contábeis e financeiros é restrita à sociedade de capital e mais severa nas de capital aberto, o mercado passa a exercer pressão externa maior sobre esse modelo societário em 
detrimento das cooperativas.

\subsection{Mensuração da eficiência}

Na literatura econômica, as medidas de eficiência são normalmente representadas por uma função de fronteiras construídas no sistema de coordenadas, em que as firmas eficientes posicionam-se necessariamente sobre a fronteira, embora, diante da existência de desperdícios, nem todas as firmas sobre a fronteira sejam eficientes. No que se refere à ótica da produção, essas firmas conseguem produzir o máximo possível dadas as suas restrições. Assim, uma medida de ineficiência seria a distância que uma unidade produtiva encontra-se abaixo da fronteira de produção.

No presente trabalho, a mensuração da eficiência foi realizada por intermédio da Análise Envoltória de Dados (DEA), com a utilização dos modelos clássicos CCR e BCC com orientação para o produto.

Na DEA, a programação matemática é utilizada para medir a eficiência em termos de distância de cada Decision Making Units (DMU) de sua respectiva fronteira de eficiência, determinada a partir dos dados da produção do conjunto de unidade. O modelo DEA com orientação-produto procura maximizar o aumento proporcional nos níveis de produto, mantendo fixa a quantidade de insumos e, de acordo com Charnes et alii (1994) e Estelita Lins e Meza (2000), pode ser representado, algebricamente, pelo seguinte Problema de Programação Linear (PPL):

$$
\begin{aligned}
& \max _{\phi, \lambda} \phi \\
& \text { s.a. } \\
& \phi y_{i}-Y \lambda \leq 0, \\
&-x_{i}+X \lambda \leq 0, \\
&-\lambda \leq 0,
\end{aligned}
$$

em que $y_{i}$ é um vetor $(m \times 1)$ de quantidades de produto da i-ésima DMU; $x_{i}$ é um vetor $(k \times 1)$ de quantidades de insumo da i-ésima DMU; $Y$ é uma matriz $(n \times m)$ de produtos das $n$ DMUs; $X$ é uma matriz $(n \times k)$ de insumos das $n$ DMUs; $\lambda$ é um vetor $(n \times 1)$ de pesos; e $\phi$ é uma escalar que tem valores iguais ou maiores do que 1 e indica o escore de eficiência das DMUs, em que um valor igual a 1 indica eficiência técnica relativa da i-ésima DMU, em relação às demais, e um valor maior do que 1 evidencia a presença de ineficiência técnica relativa. $O(\phi-1)$ indica o aumento proporcional nos produtos que a i-ésima DMU pode alcançar, mantendo constante a quantidade de insumo.

O problema apresentado em (1) é resolvido $n$ vezes, sendo uma vez para cada DMU, e, como resultado, apresenta os valores de $\phi$ e $\lambda$, sendo $\phi$ o escore de eficiência da DMU sob análise e $\lambda$ fornece as DMUs eficientes que servem de referência ou benchmark para a i-ésima DMU ineficiente.

No intuito de incorporar a possibilidade de retornos variáveis à escala, Banker et alii (1984) propuseram o modelo BCC da análise envoltória de dados, introduzindo uma restrição de convexidade no modelo CCR, apresentado no PPL (1).

Enquanto o modelo CCR considera retornos constantes à escala, o modelo BCC considera retornos variáveis à escala. Dessa forma, o enfoque do modelo permite captar os efeitos ao longo da função de produção decorrentes de alterações na escala de produção.

O modelo BCC, apresentado no PPL (2), é menos restritivo do que o modelo CCR e permite, de acordo com Banker e Thrall (1992), decompor a eficiência técnica em eficiência de escala e "pura" eficiência técnica.

Para analisar a eficiência de escala, torna-se necessário estimar a eficiência das DMUs, utilizandose tanto o modelo CCR (1) como o BCC (2). A ineficiência de escala é evidenciada quando existem diferenças no escore desses dois modelos, o que determina um retorno variável, que exige para sua correta classificação, entre não-crescente e não-decrescente, outra estimação considerando pelo menos 
um desses comportamentos, via inclusão de restrições no PPL original (Färe et alii, 1994, Estelita Lins e Meza, 2000).

Embora se tenha optado por essa abordagem, vale ressaltar a existência de diversas outras alternativas de mensuração da eficiência de escala, discorridas em Banker $(1984)$, Banker et alii $(1984,1996)$ e Golany e Yu (1997).

O modelo BCC, que pressupõe retornos variáveis à escala e orientação-produto, pode ser representado pela seguinte notação algébrica:

$$
\begin{aligned}
& \max _{\phi, \lambda} \phi \\
& \text { s.a. } \\
& \phi y_{i}-Y \lambda \leq 0, \\
&-x_{i}+X \lambda \leq 0, \\
& N 1^{\prime} \lambda=1, \\
&-\lambda \leq 0,
\end{aligned}
$$

em que N1 é um vetor (nx1) de números uns. As demais variáveis foram descritas, anteriormente.

Conforme ressaltado por Belloni (2000), os modelos CCR e BCC apresentam regiões de viabilidade distintas. A região viável do modelo BCC é restrita às combinações convexas dos planos de produção observados, o que é caracterizado pelos retornos variáveis à escala. Como consequiência, considerando orientação ao produto, o indicador de eficiência do modelo BCC é menor ou igual ao indicador de eficiência do modelo CCR.

Do modelo CCR - Produto é possível obter a eficiência técnica sobre o pressuposto de retornos constantes à escala (RCE), também denominada medida de produtividade global ou eficiência produtiva.

Do modelo BCC - Produto extrai-se a medida de eficiência técnica (ET) sobre o pressuposto de retornos variáveis à escala (RVE).

A eficiência de escala é calculada pela relação entre eficiência técnica sobre o pressuposto de retornos constantes à escala (RCE) e eficiência técnica sobre o pressuposto de retornos variáveis à escala (RVE), conforme a Equação 3.

$$
E_{S}=\frac{E t_{R C E}\left(X_{K}, Y_{K}\right)}{E t_{R V E}\left(X_{K}, Y_{K}\right)}
$$

em que $E t_{R C E}\left(X_{K}, Y_{K}\right)$ é a eficiência técnica ou produtiva (CCR); $E t_{R V E}\left(X_{K}, Y_{K}\right)$ a eficiência técnica (BCC); e $E_{S}\left(X_{K}, Y_{K}\right)$ a eficiência de escala.

Na composição da matriz de insumos e produtos, buscou-se utilizar quesitos já validados por outros estudos, como os de Porter e Scully (1987), Ferrier e Porter (1991), Ariyaratne (1997), Singh et alii (2000), Sueyoshi et alii (1998) e Tupy et alii (2004), privilegiando aquelas variáveis que permitiam comparação entre cooperativas e sociedades de capital.

Nesse ponto, torna-se relevante destacar a predileção pelos registrados quantitativos legais, a exemplo de relatórios financeiros, mesmo diante da limitação de se expor ao viés contábil e fiscal, fruto da utilização de proxies monetárias na mensuração da eficiência. Essa construção se deve, em parte, ao fato de a unidade física não incorporar o valor intelectual da atividade, como ocorre com o fator trabalho, necessitando-se de um fator de ponderação, daí o valor monetário. Isso é facilmente compreendido quando se evidencia no relatório financeiro que uma hora-máquina-operador é abruptamente inferior à uma hora-máquina-gerente de produção, visto que a unidade monetária age no sentido de ponderar a contribuição efetiva dos fatores.

No caso da produção, a agravante está no fato de as empresas produzirem uma cesta de diferentes produtos, entre uma infinidade de alternativas, e não apenas um produto, o que impossibilitaria a 
utilização de variáveis físicas; mais uma vez a moeda age como fator de ponderação, no sentido se atingir uma medida mais próxima, embora não exata, de eficiência técnica.

Nessa ótica, tomando-se por base as características peculiares dos registros da atividade láctea, foi escolhido o conjunto de variáveis que compuseram a análise da eficiência, sendo elas:

\section{Produtos (Y)}

- Faturamento do setor de lácteos em R\$, representando uma proxy de produção da DMU.

- Resultado operacional em RS, representando uma proxy de resultado global líquido da DMU.

\section{Insumos (X)}

- Quantidade de leite processado em litros, representando a matéria-prima principal da indústria de laticínios.

- Gasto total com empregados, em R\$, representando o fator trabalho, ponderado monetariamente pela contribuição produtiva.

- Ativo permanente total, em R\$, representando uma proxy do capital.

- Número de fornecedores, em unidades, representando uma proxy dos custos de transação.

Ressalta-se que todas as variáveis referem-se a dados anuais, com exceção do número de fornecedores e empregados, que se refere à média anual devido ao impacto das alterações destes na capacidade de operacionalização da sociedade, em razão dos aspectos sazonais da atividade.

\subsection{Determinantes da eficiência nas cooperativas}

O modelo econométrico Tobit foi utilizado para investigar os fatores que mais contribuem para explicar os escores de eficiência associados às sociedades cooperativas e às sociedades de capital. Segundo Greene (2002), o modelo Tobit é usado nos casos em que a variável dependente está compreendida entre certos valores ou concentrada em pontos iguais a um valor-limite. Usando com propriedade os termos estatísticos, há nesses casos o que se chama de amostra censurada. Nessas situações, a aplicação do modelo Tobit visa contornar o problema da censura valendo-se de técnicas estatísticas que possibilitem fazer inferências para toda a população sem perda de qualidade, como ocorria no caso de variáveis truncadas.

De acordo com Greene (2002), é possível definir as variáveis explicativas do modelo Tobit por $X=$ $\left(x_{1}, \ldots, x_{p}\right)$, sendo a variável de resposta definida por $Y^{*}$ (representando o $Y$ observado através dos escores de eficiência da abordagem DEA). Desse modo, tem-se o modelo formulado como $Y_{i}^{*}=X_{1} \beta+$ $u_{i}$, em que se observa efetivamente a variável $y$, sendo $u_{i}$ o erro aleatório da equação. 0 valor da censura é denotado por $Y_{i}^{c}$, em que o subscrito $i$ indica a censura em cada observação. Assim, o que se observa na amostra é:

$$
\left\{\begin{array}{lll}
y_{i}=y_{i}^{*} & \text { se } & y_{i}^{*}<y_{i}^{c} \\
y_{i}=y_{i}^{c} & \text { se } & y_{i}^{*} \geq y_{i}^{c}
\end{array}\right.
$$

É importante ressaltar que, nesse caso, a estimação dos parâmetros $\beta$ 's pelo método de MQO (mínimos quadrados ordinários) resultaria em parâmetros viesados, pois a censura introduz correlação entre o termo do erro da regressão e as covariadas ( $X$ 's). Assim, a esperança do erro deve ser calculada como uma esperança condicional, representada por $E\left\lfloor u_{i} \mid u_{i}<y_{i}^{c}-X_{I} \beta\right\rfloor$.

A alternativa mais adequada para a construção de estimadores consistentes, neste caso, é estimar os parâmetros $\beta$ 's do modelo de regressão por meio do método de máxima verossimilhança. Procedendo 
Tabela 2 - Variáveis explicativas do modelo de eficiência

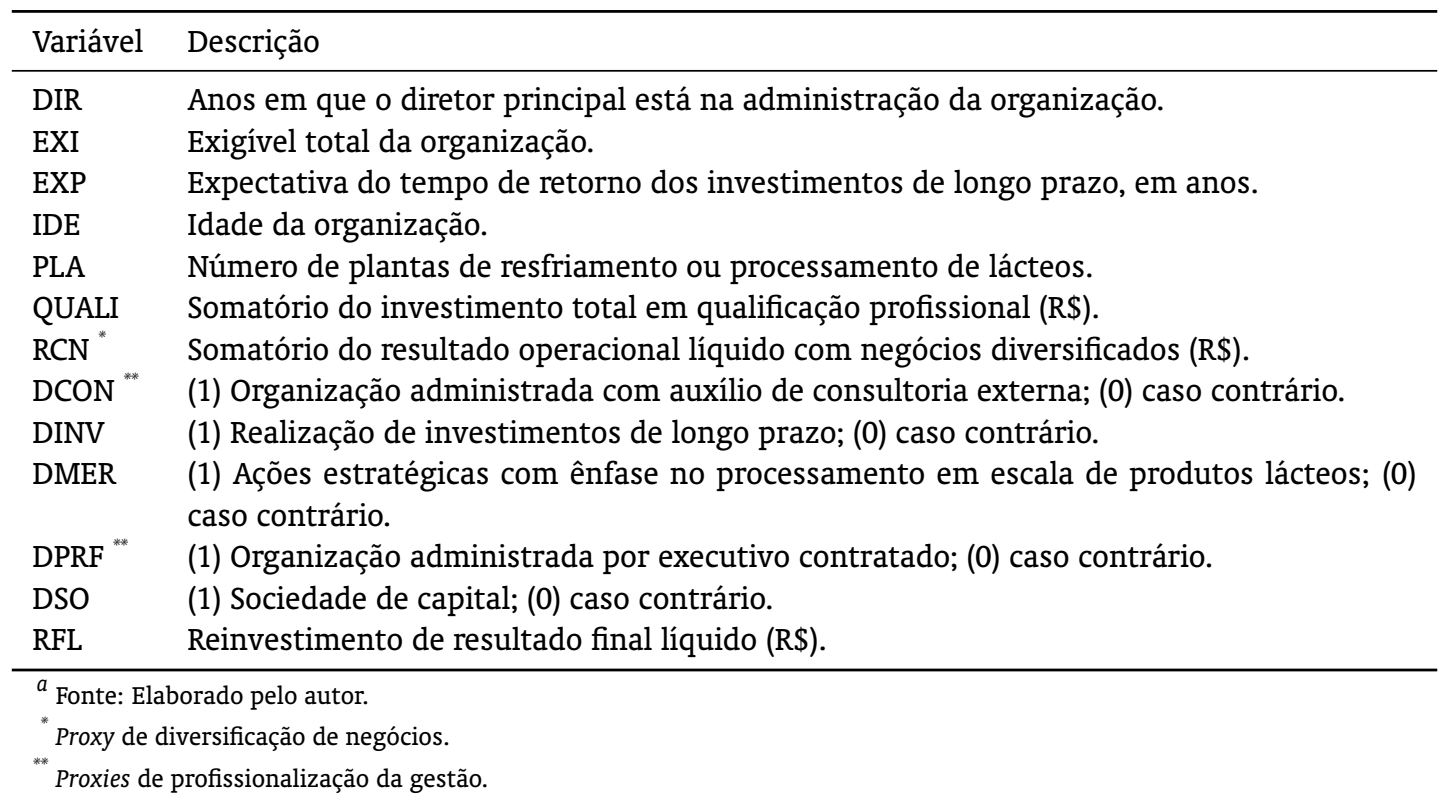

desse modo, torna-se possível isolar e descrever a contribuição das variáveis censuradas, bem como das não-censuradas, na formação da função de verossimilhança.

Na determinação dos condicionantes da eficiência, foram empregados como variável dependente $(\mathrm{Y})$ os escores de eficiência obtidos por meio da Análise Envoltória de Dados. Já as variáveis explicativas (X) foram determinadas com base no referencial teórico, estando representadas na Tabela 2.

\section{RESULTADOS E DISCUSSÃO}

\subsection{Análise da eficiência}

As 107 unidades produtivas que compuseram a amostra foram formadas por 59 sociedades cooperativas e 48 sociedades de capital, distribuídas por 15 estados do território nacional que responderam ao questionário da pesquisa entre os meses de maio e setembro de 2004.

Na Tabela 3 são apresentadas as variáveis empregadas no modelo de eficiência, juntamente com suas estatísticas descritivas.

Pela média dos escores de eficiência produtiva, exposta na Tabela 4, é possível visualizar o grau de ineficiência das organizações, possibilitando aos agentes públicos e privados traçar políticas que estimulem a melhoria da performance do setor.

Os resultados demonstram que tanto as sociedades de capital quanto as cooperativas apresentaram considerável grau de ineficiência técnica e de escala.

De modo geral, as cooperativas foram menos eficientes no quesito eficiência produtiva, embora no quesito eficiência de escala, elas tenham apresentado melhor desempenho que as sociedades de capital.

A média da eficiência produtiva foi 0,448 e 0,580 para cooperativas e sociedades de capital, respectivamente (Tabela 4), o que sugere a possibilidade de aumento significativo de produção considerando a mesma proporção de insumos atualmente utilizada, tomando como referência a orientação produto do modelo. 
Tabela 3 - Estatística descritiva das variáveis empregadas no modelo de eficiência das cooperativas e sociedades de capital

\begin{tabular}{lcccc}
\hline Variável (1.000 R\$/ano) & Média & Desvio-Padrão & Máximo & Mínimo \\
\hline Faturamento do setor de laticínios & $246.942,05$ & $485.605,31$ & $2.820 .805,68$ & 120 \\
Resultado operacional líquido & $297.039,07$ & $80.026,61$ & $2.390 .581,49$ & $-7.108,38$ \\
Ativo permanente & $85.798,12$ & $244.673,52$ & $2.336 .640,23$ & 114,86 \\
Folha de pagamento & $6.711,82$ & $12.563,46$ & $78.621,60$ & 38 \\
Leite processado (1/dia) & 76.305 & 127.686 & 850.000 & 1.300 \\
Número de produtores & 502 & 829 & 6.000 & 2 \\
\hline
\end{tabular}

${ }^{a}$ Fonte: Resultados da pesquisa.

Tabela 4 - Escores de eficiência técnica e de escala na indústria de laticínios do Brasil

\begin{tabular}{lccccc}
\hline & Unidades eficientes (\%) & Média & Desvio-padrão & Máximo & Mínimo \\
\hline $\begin{array}{l}\text { Sociedade cooperativa } \\
\text { Eficiência técnica }\end{array}$ & 20 & 0,448 & 0,316 & 1 & 0,512 \\
Eficiência de escala & 54 & 0,823 & 0,225 & 1 & 0,454 \\
\hline $\begin{array}{l}\text { Sociedade de capital } \\
\text { Eficiência técnica }\end{array}$ & 27 & 0,58 & 0,331 & 1 & 0,519 \\
Eficiência de escala & 38 & 0,65 & 0,35 & 1 & 0,364 \\
\hline Agregado & & & & & \\
Eficiência técnica & 23 & 0,507 & 0,328 & 1 & 0,512 \\
Eficiência de escala & 47 & 0,745 & 0,299 & 1 & 0,364 \\
\hline
\end{tabular}

Fonte: Resultados da pesquisa.

Para comparar o grau de ineficiência da unidade produtiva tomando por base o escore da média de eficiência técnica, foi construído o indicador definido por Ferrier e Porter (1991), como segue:

$$
\left(\frac{1}{\text { score }}-1\right) x 100
$$

Assim, é possível dizer que o lapso médio de eficiência técnica nas sociedades cooperativas requer uma utilização de recursos $123 \%$ maior que as cooperativas que estão operando sobre a curva eficiente de produção. No caso das sociedades de capital, esse lapso médio de eficiência representa 72,41\%, indicando menor desperdício em comparação com as cooperativas.

A média da eficiência de escala foi de 0,823 e 0,650 para cooperativas e sociedades de capital, respectivamente (Tabela 4), indicando que as unidades produtivas podem ter resultado melhor se operarem em melhor escala.

Em razão de ser a DEA uma abordagem determinística, qualquer resultado diferente da plena eficiência pode ser interpretado como ineficiência, o que oportuniza a emergência de DMUs pseudo-eficientes e pseudo-ineficientes, resultantes de erros de coleta de dados ou fatores atribuídos ao acaso, comprometendo as estimativas realizadas sobre os escores de eficiência Xue e Harker (1999); Donf e Featherstone (2004). Visando corrigir essa limitação, vários trabalhos, a exemplo de exemplo de Efron (1987), Efron e Tibshirani (1993), Xue e Harker (1999); Löthgren e Tambour (1999); Souza e Tabak (2002), têm sugerido a utilização do bootstrap para a correção dessa limitação, por ser um procedimento mais refinado 
que o teste de média, em razão, principalmente, das milhares de iterações possíveis na abordagem de reamostragem.

Após 1.000 iterações, foram construídos intervalos de confiança a 90\% de probabilidade para as médias de eficiência das cooperativas e sociedades de capital, conforme apresentado na Tabela 5.

Tabela 5 - Intervalo de confiança, sob a abordagem de bootstrap, para as médias de eficiência técnica e de escala.

\begin{tabular}{lccc}
\hline & & \multicolumn{2}{c}{ Intervalo de Confiança (90\%) } \\
\hline & Média observada & Mínimo & Máximo \\
\hline Sociedades cooperativas & & & \\
Eficiência técnica & 0,448 & 0,386 & 0,519 \\
Eficiência de escala & 0,823 & 0,769 & 0,864 \\
\hline Sociedades de capital & & & \\
Eficiência técnica & 0,58 & 0,532 & 0,652 \\
Eficiência de escala & 0,65 & 0,559 & 0,723 \\
\hline
\end{tabular}

Fonte: Resultados da pesquisa.

Os resultados permitem afirmar, considerando um intervalo de confiança de $90 \%$ de probabilidade, que as sociedades de capital são mais eficientes que as cooperativas no quesito produtividade, assim como asseveram a maior eficiência das cooperativas no quesito escala.

\subsection{Variáveis associadas à eficiência}

Foram estimadas duas regressões utilizando os escores de eficiência produtiva (Y) e de escala (Ys) como variáveis dependentes. Nesse ponto foi utilizado, conforme metodologia sugerida por Xue e Harker (1999), o procedimento de bootstrap para corrigir o problema de violação da hipótese de independência entre as variáveis explicadas; à exceção da variável DCON, presente na Tabela 8 , todas as demais se mostraram significativas em nível inferior a $10 \%$.

Os determinantes da eficiência foram investigados partindo-se da premissa de que o leite é uma commodity e de que a tecnologia de processamento de seus derivados é amplamente difundida.

Desse modo, o sucesso da organização é condicionado, em tese, pela profissionalização da administração, pelo modelo de gestão, pelo perfil da organização e de seus dirigentes e pelos diversos fatores societários que determinam o acesso à tecnologia e ao financiamento produtivo, fatores esses discorridos na teoria da agência e dos direitos de propriedade. Outras variáveis incorporadas dizem respeito à diversificação, à agregação de valor, ao posicionamento estratégico, à qualidade dos recursos humanos e à experiência empresarial.

Na Tabela 6 é possível visualizar as estatísticas descritivas das variáveis independentes utilizadas nos modelos de análise censurada - Tobit.

Os resultados do modelo Tobit para análise da eficiência técnica e de escala na indústria de laticínios podem ser observados nas Tabelas 7 e 8 , respectivamente.

Os coeficientes estimados por meio do modelo apresentaram ajustamento satisfatório, indicando que as variáveis incorporadas têm considerável poder para explicar o fenômeno em estudo, conforme verificado pelo nível de significância do teste de, que foi significativo a $1 \%$ de probabilidade.

Dentre os fatores que tiveram influência na eficiência técnica, ressalta-se a variável DSO, corroborando a tese de maior eficiência das sociedades de capital. Deve-se destacar o investimento em qualificação (QUALI), que permite afirmar que maior investimento em qualificação está diretamente associado à eficiência técnica. Desse modo, cada unidade de Real (R\$) investida em cursos e treinamentos dos empregados está associada à elevação positiva na medida de eficiência técnica das organizações. 
Tabela 6 - Variáveis utilizadas no modelo de análise de eficiência da indústria de laticínios

\begin{tabular}{lcccc}
\hline Variável & Média & Desvio-padrão & Mínimo & Máximo \\
\hline DIR & 10,17 & 7,72 & 1 & 36 \\
EXI & $9.439 .026,65$ & $17.072 .897,48$ & $2.800,00$ & $97.896 .829,00$ \\
EXP & 40,71 & 42,05 & 0 & 180 \\
IDE & 30,5 & 16,57 & 1 & 64 \\
PLA & 1,42 & 0,99 & 1 & 6 \\
QUALI & $37.262,18$ & $73.750,20$ & 0 & $523.312,51$ \\
RCN & $17.899 .772,83$ & $63.070 .680,06$ & -24.169 .00 & 541.458 .347 \\
DCON & 0,18 & 0,38 & 0 & 1 \\
DINV & 0,31 & 0,46 & 0 & 1 \\
DMER & 0,24 & 0,43 & 0 & 1 \\
DSO & 0,45 & 0,5 & 0 & 1 \\
RFL & 0,78 & 0,42 & 0 & 1 \\
\hline
\end{tabular}

DIR: número de anos que o administrador principal está à frente da organização. EXI: exigível total; EXP: expectativa de retorno sobre investimento, em anos; IDE: idade da DMU; PLA: número de plantas; QUALI: investimento em qualificação de empregados; RCN: resultado operacional líquido com negócios diversificados; DCON: dummy de consultoria à administração; DINV: dummy de investimentos de longo prazo; DMER: dummy de ações estratégicas para a produção em escala; DSO: dummy de modelo societário; RFL: reinvestimento de resultado final líquido. Fonte: Resultados da pesquisa.

Tabela 7 - Fatores associados à eficiência técnica na indústria de laticínios

\begin{tabular}{lcccc}
\hline Variável & Coef. Estimado & Erro-padrão & Probabilidade & Efeito marginal \\
\hline C & 33,027866 & 8,7255561 & 0 & 31,786461 \\
EXI & $-0,0000006$ & 0,0000003 & 0,045 & $-0,0000006$ \\
RCN & $-0,0000003$ & 0,0000001 & 0 & $-0,0000003$ \\
DMER & 17,14549 & 6,8423198 & 0,012 & 16,501049 \\
DSO & 21,390963 & 6,2600268 & 0,001 & 20,58695 \\
DCON & 13,383963 & 7,7754985 & 0,085 & 12,880905 \\
RFL & 11,376915 & 6,733319 & 0,091 & 10,949296 \\
QUALI & 0,0003409 & 0,0000875 & 0 & 0,0003281 \\
PLA & $-6,5646448$ & 3,1171753 & 0,035 & $-6,3179021$ \\
$\chi^{2}=33,15$ & & & 0 & \\
\hline
\end{tabular}

Fonte: Resultados da pesquisa. 
A gestão profissional, por meio de consultorias especializadas (DCON), está diretamente associada a ganhos de eficiência na organização. Assim, unidades produtivas que contam com apoio de profissionais especializados nas áreas de produção e comercialização de produtos lácteos têm melhor desempenho que organizações que não gozam desse apoio.

Percebe-se uma associação positiva entre eficiência técnica e reinvestimento de resultados líquidos (RFL). Devido às elevadas taxas de juros dos financiamentos, a melhor alternativa de captação ainda tem sido a incorporação de parte dos resíduos financeiros líquidos (RFL), medidos pelas sobras operacionais líquidas ou lucro líquido, o que depõe a favor da eficiência.

O significativo impacto negativo da variável (EXI) vem corroborar essa observação, uma vez que aumentos de passivos exigíveis, representando o nível de endividamento, têm impactos negativos sobre a eficiência técnica. Dessa forma, cada unidade de Real (R\$) a mais de exigível está inversamente associada à eficiência técnica da organização.

Outro fator que tem contribuído, sobremaneira, para a redução da eficiência técnica tem sido a dedicação a outros negócios, medidos pela diversificação (RCN). A explicação pode advir de deseconomias de escopo derivadas da baixa relação entre os negócios diversificados na indústria de laticínios.

O número de plantas (PLA) de resfriamento ou processamento tem impacto negativo sobre a eficiência técnica. Cada nova planta tem a propriedade de diminuir a eficiência em 6,32 pontos percentuais.

Considerando que a maior parte (85\%) das unidades produtivas opera em retornos crescentes, podese inferir a ociosidade operacional dessas plantas. Nesse sentido, é de se esperar que o aumento no número de plantas concorra negativamente para a eficiência à medida que os custos operacionais se elevem significativamente pelo aumento no uso de capital e trabalho.

Os resultados parecem indicar que o foco de eficiência está na concentração no negócio leite e no processamento em escala. Por isso, foi possível identificar uma relação positiva entre as ações estratégicas para o aumento do processamento em escala (DMER) sobre a eficiência técnica na indústria de laticínios, conforme verificado na Tabela 7.

Na Tabela 8 são apresentados os fatores associados à eficiência de escala na indústria de laticínios. A variável DSO destaca a menor eficiência de escala das sociedades de capital em comparação com as sociedades cooperativas. A variável DCON corrobora o impacto da gestão profissional na eficiência da organização, reflexo da orientação de profissionais especializados no dimensionamento produtivo da organização.

Tabela 8 - Fatores associados à eficiência de escala na indústria de laticínios do Brasil

\begin{tabular}{lcccc}
\hline Variável & Coef. Estimado & Erro-padrão & Probabilidade & Efeito marginal \\
\hline C & 87,278893 & 6,8234016 & 0 & 87,176808 \\
DIR & 1,530807 & 0,3384176 & 0 & 1,5290165 \\
IDE & $-0,3025806$ & 0,1456299 & 0,038 & $-0,3022267$ \\
DINV & $-13,311212$ & 5,3881196 & 0,014 & $-13,295644$ \\
EXP & $-0,1599073$ & 0,058365 & 0,006 & $-0,1597203$ \\
DCON & 10,839444 & 6,6455139 & 0,103 & 10,826766 \\
DSO & $-23,242735$ & 5,3668512 & 0 & $-23,21555$ \\
$\chi^{2}=51,40$ & & & 0 & \\
\hline
\end{tabular}

Tanto os investimentos (DINV) quanto as expectativas de longo prazo sobre os investimentos (EXP) apresentam impacto negativo sobre a eficiência de escala. Cada ano de dilatação da expectativa de retorno está associado à diminuição de 0,159 ponto percentual na eficiência da organização.

Esse fator deve ser avaliado com muita cautela. Em primeira instância, poder-se-ia asseverar que ele está associado ao fato de esses investimentos serem voltados à capacidade produtiva, o que depõe contra a eficiência, em razão de a maior parte das unidades produtivas estar operando em retornos 
crescentes e, como tal, em condições de aproveitar melhor sua capacidade produtiva. No entanto, uma inferência metodológica poderia evitar conclusões precipitadas, uma vez que o impacto de um investimento sobre a eficiência de escala tem reflexos de longo prazo (positivo ou negativo); como o trabalho está pautado em seção-cruzada, não permite fazer inferências temporais. Desse modo, investimentos produtivos podem, no curto prazo, diminuir a eficiência, em razão de a firma, operando com retornos crescentes, elevar o estoque de capital, pari passu, aos passivos exigíveis (endividamento). Todavia, no longo prazo, os benefícios podem advir do processamento em maior escala, da tecnologia mais ajustada e da melhor competitividade na indústria.

A experiência na indústria de laticínios, medida pelos anos em que o diretor principal se encontra à frente da organização (DIR), apresenta os efeitos da curva de aprendizagem sobre o ajustamento da escala de produção. Cada ano de experiência acumulada na administração da organização está associado à elevação de 1,53 ponto percentual na eficiência da unidade produtiva.

O conceito de "curva de aprendizagem" resulta da idéia de que a construção de eficiência na unidade produtiva requer tempo - o tempo necessário para aprendizagem do processo produtivo. Esse conceito está intimamente ligado à idéia de que os gestores incorporam o conhecimento com tempo e, nesse sentido, utilizam com maior proficiência os recursos produtivos.

A idade da organização (IDE) é uma variável de expectativas ambíguas. Poder-se-ia esperar associação positiva com a eficiência, em virtude da consolidação da organização no setor de lácteos e dos ajustamentos produtivos ocorridos ao longo de sua existência. Poder-se-ia esperar também, de forma mais objetiva, impacto negativo, associado ao fato de as organizações mais novas operarem com tecnologias mais recentes, que diminuem custos por serem mais parcimoniosas em recursos operacionais, como o fator trabalho, que pesa expressivamente no cálculo da eficiência. Cada ano de existência da organização está associado à redução de 0,304 ponto percentual na eficiência de escala. A constatação de correlação negativa e significativa entre eficiência e idade demonstrou que as firmas mais novas são realmente mais eficientes, o que parece sustentar a segunda hipótese levantada, corroborando assim os resultados do trabalho.

\section{CONCLUSÕES}

Os resultados demonstraram que, no agregado, as cooperativas foram mais eficientes em termos de escala e menos eficientes no quesito produtivo.

Uma das justificativas para a maior eficiência de escala das cooperativas está associada à sua maior capacidade de coordenação na cadeia produtiva. Isto é, enquanto as sociedades de capital têm que acessar constantemente o mercado spot para compor e recompor a sua capacidade de processamento, em função da sazonalidade da oferta de leite, as cooperativas prescindem dessa etapa, visto que os cooperados já estão associados à sua unidade produtiva, o que facilita a exploração da capacidade processadora.

Entre as variáveis de destaque na promoção da eficiência encontram-se a qualificação profissional e o apoio especializado à gestão, representadas por consultorias especializadas, demonstrando de forma inequívoca os benefícios associados às ações de profissionalização como forma de garantir maior eficiência da organização. Esses resultados confirmam que as organizações que contam com apoio de profissionais especializados têm melhor desempenho que as que não desfrutam desse apoio, o que motiva políticas qualitativas para o setor.

Por fim, o trabalho assevera a importância de se promoverem políticas diferenciadas para a melhoria da eficiência na indústria de laticínios, em função das particularidades dos modelos societários e das unidades produtivas. 


\section{Referências Bibliográficas}

Ariyaratne, C. (1997). An analysis of efficiency and productivity of midwestern agricultural cooperatives. Dissertação de mestrado, M.S. of Agricultural Economics, Manhattan, KS.

Banker, R. D. (1984). Estimating most productive scale size using data envelopment analysis. European Journal of Operational Research, 17:35-44.

Banker, R. D., Change, H., \& Cooper, W. W. (1984). Some models for estimating technical and scale inefficiencies in data envelopment analysis. Management Science, 30(9):1078-1092.

Banker, R. D., Change, H., \& Cooper, W. W. (1996). Equivalence and implementation of alternative methods for determining returns to scale in data envelopment analysis. European Journal of Operational Research, 89:473-481.

Banker, R. D. \& Thrall, R. M. (1992). Estimation of returns to scale using dea. European Journal of Operational Research, 62(1):74-84.

Belloni, J. A. (2000). Uma metodologia de avaliação da eficiência produtiva de universidade federais brasileiras. Tese de Doutorado, Universidade Federal de Santa Catarina, Florianópolis, SC.

Charnes, A., Cooper, W. W., Lewin, A. Y., \& Seiford, L. M. (1994). Data envelopment analysis: theory, methodology, and application. Dordrecht: Kluwer Academic.

Condon, A. M. (1987). Cooperative theory: new approaches, chapter The methodology and requirements of a theory of modern cooperative enterprise, pages 1-32. US Dept. of Agriculture.

Donf, F. \& Featherstone, A. (2004). Technical and scale efficiencies for chinese rural credit cooperatives: a bootstrapping approach in data envelopment analysis. Technical report, Center for agricultural and rural development.

Efron, B. (1987). Better bootstrap confidence intervals. Journal of the American Statistical Association, (82):171-185.

Efron, B. \& Tibshirani, R. (1993). An introduction to the bootstrap. Chapman and Hall, New York.

Estelita Lins, M. P. \& Meza, L. A. (2000). Análise envoltória de dados. Technical report, COPPE/UFRJ, Rio de Janeiro.

Fama, E. F. \& Jensen, M. C. (1983). Separation of ownership and control. Journal of Law and Economics, (26):301-325.

Ferrier, G. D. \& Porter, P. K. (1991). The productive efficiency of us milk processing co-operatives. Journal of Agricultural Economics, (42):161-173.

Färe, R., Grosskopf, S., \& Lovell, C. K. (1994). Production frontiers. Cambridge University Press.

Golany, B. \& Yu, G. (1997). Estimating returns to scale in dea. European Journal of Operational Research, (103):28-37.

Greene, W. H. (2002). Econometric analysis. Macmillan, New York, 5 edition.

Jensen, M. C. \& Meckling, W. H. (1979). Rights and production functions: an application to labormanaged firms and codetermination. Journal of Business, (52):469-506.

Löthgren, M. \& Tambour, M. (1999). Testing scale efficiency in dea models: a bootstrapping approach. Applied Economics, (31):1231-1237. 
Nilsson, J. (1999). Organizational principles for cooperative firms. Scandinavian Journal of Management, (17):329-356.

Porter, P. K. \& Scully, G. W. (1987). Economic efficiency in cooperatives. The Journal of Law and Economics, (30):489-512.

Shleifer, A. \& Vishny, R. W. (1996). A survey of corporate governance. National Bureau of Economics Research, Cambridge, MA.

Singh, S., Fleming, E., \& Coelli, T. (2000). Efficiency and productivity analysis of cooperative dairy plants in haryana and punjab states of india. Working Paper Series 2, Agricultural and Resource Economics.

Souza, G. S. \& Tabak, B. M. (2002). Factors affecting the technical efficiency of production of the brazilian banking system: a comparison of four statistical models in the context of dea. Technical Report 17, Banco Central do Brasil.

Sueyoshi, T., Hasebe, T., Ito, F., Salai, J., \& Ozawa, W. (1998). Dea-bilateral performance comparison: an application to japan agricultural co-operative. Omega - International Management Science, 26(2):233248.

Sykuta, M. \& Cook, M. L. (2001). A new institutional economics approach to contracts and cooperatives. American Journal of Agricultural Economics, 83(5):2-19.

Tupy, O., Vieira, M. C., \& Esteves, S. N. (2004). Eficiência relativa de cooperativas de laticínios. Congresso Brasileiro de Economia e Sociologia Rural.

Xue, M. \& Harker, P. T. (1999). Overcoming the inherent dependency of dea efficiency scores: a bootstrap approach. Technical report, The Wharton Financial Institutions Center. 